\title{
Dilma Rousseff no Jornal Nacional: a construção do ethos político e jornalístico na entrevista política televisiva
}

[Dilma Rousseff in the Jornal Nacional: the construction of the political and journalistic ethos in the television political interview]

\author{
Bruno Araújo \\ Universidade de Brasília \\ [University of Brasilia]
}

\author{
Adriano Lima Feitosa \\ Universidade de Brasília \\ [University of Brasilia]
}

\section{Giovanna Maria Silva}

Universidade de Brasília

[University of Brasilia]

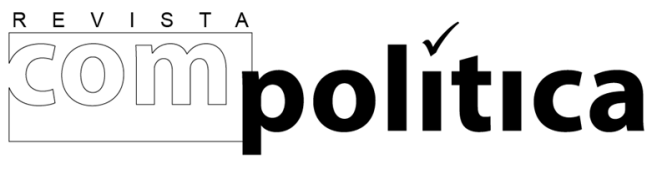

revista compolítica

2017, vol. 7(2)

compolitica.org/revista

ISSN: 2236-4781

DOI: 10.21878/compolitica.2017.7.2.302 () Open Access Journal

\author{
Bruno Henrique Oliveira \\ Universidade de Brasília \\ [University of Brasilia]
}

\author{
Úrsula Barbosa Rodrigues \\ Universidade de Brasília \\ [University of Brasilia]
}

\begin{abstract}
Resumo
No âmbito dos estudos sobre mídia e política, este trabalho propõe analisar a entrevista do Jornal Nacional, da TV Globo, com a então candidata à reeleição pelo Partido dos Trabalhadores, Dilma Rousseff, nas eleições gerais de 2014. Partindo dos estudos de Pierre Bourdieu, pretende-se estudar a interação entre os campos político e jornalístico, com particular interesse pelas estratégias discursivas de constituição de seus respectivos ethos no contexto da entrevista política televisiva. Esse gênero jornalístico é encarado como estrutura comunicacional dialógica que, no caso concreto, revelou condições de interlocução desiguais entre os campos, em função de os jornalistas incorporarem valores negativos em relação à política, provenientes da cultura política nacional. Tais valores funcionaram, no âmbito da entrevista, como elementos constitutivos de um ethos negativo prévio em relação ao campo político.
\end{abstract}

Palavras-chave: Campo Político, Campo Jornalístico, Ethos, Entrevista Política.

\begin{abstract}
In the context of the studies on media and politics, this work proposes to analyze the interview of the Jornal Nacional of TV Globo with the candidate for reelection by the Workers' Party, Dilma Rousseff, in the general elections of 2014. Starting from Pierre Bourdieu's studies, we analyze the interaction between both fields, with particular interest in the discursive strategies of constitution of ethos of both fields in the context of the television political interview. This type of journalism genre is seen as a dialogical communicational structure that, in this case, it revealed unequal conditions of interlocution between the fields, as journalists incorporated negative values in relation to politics, originating from the national political culture, which functioned as constitutive of a negative ethos in relation to the political field.
\end{abstract}

Keywords: Political Field, Journalistic Field, Ethos, Political Interview. 


\title{
Dilma Rousseff no Jornal Nacional: a construção do ethos político e jornalístico na entrevista política televisiva
}

\author{
Bruno ARAÚJO \\ Adriano Lima FEITOSA \\ Giovanna Maria SILVA \\ Bruno Henrique OLIVEIRA \\ Úrsula Barbosa RODRIGUES
}

análise do papel do jornalismo no contexto das campanhas eleitorais não é um
tema novo. De fato, em cada período eleitoral, diversos autores analisam o tipo
de cobertura realizada pela mídia, tentando perceber os significados construídos

e, eventualmente, as implicações da cobertura sobre os resultados imediatos da corrida eleitoral e sobre o destino político do país nos anos seguintes. Em 2014, as eleições brasileiras foram marcadas por uma polarização política que parece ter dominado inclusive parte da cobertura jornalística realizada pelos principais meios de comunicação nacionais. Naquele contexto eleitoral atípico, o Jornal Nacional, da TV Globo, telejornal de maior audiência no Brasil, realizou um conjunto de entrevistas com os candidatos à Presidência da República, adotando um tom de confronto que gerou bastante polêmica na opinião pública, particularmente entre os estudiosos da mídia. Na análise do professor Venício A. de Lima (2014), não houve jornalismo nas entrevistas realizadas:

\begin{abstract}
Não houve jornalismo. Não houve conversa, mas um combate. Não houve perguntas, mas ataques. Os "entrevistados" foram fustigados e provocados pelos "entrevistadores" como se estivessem em um duelo público. Nenhuma das regras elementares para a condução de uma entrevista jornalística foi cumprida (...) A postura dos "entrevistados" implicava a aceitação da inevitabilidade de serem (os entrevistados) submetidos a uma inquisição pública em rede nacional de televisão, sem qualquer garantia sobre a forma como seriam "tratados" e/ou em relação à equidade do tempo concedido para resposta das "perguntas" feitas ao vivo (Lima, 2014).
\end{abstract}

De fato, uma visão preliminar permite observar o nível de conflitualidade inerente àquela entrevista. Assumimos, como hipótese em construção, que o tom de confronto agudo adotado pelos jornalistas William Bonner e Patrícia Poeta não estava alheio ao processo de polarização que se desenhava naquele período eleitoral, tendo sido acelerado nos meses 
posteriores. Nessa medida, pretende-se compreender como se estruturou a relação entre os campos político e jornalístico na entrevista do Jornal Nacional com Dilma Rousseff, com especial foco nas estratégias utilizadas por ambos os campos para a constituição de seu ethos perante a opinião pública. Entendemos que, em função dos acontecimentos posteriores, que culminaram com a cassação da presidente, em agosto de 2016, esta entrevista possui um valor histórico importante que justifica uma exploração analítica mais detida.

O texto dialoga com a teoria dos campos de Bourdieu (2007) para discutir as particularidades do campo político e do campo jornalístico, com ênfase nas tensões observadas entre ambos no contexto da entrevista política. Por outro lado, discutiremos o conceito de ethos e sua relação com a entrevista política, vista aqui como uma estrutura comunicacional que se converte em palco de uma luta simbólica entre agentes políticos e jornalísticos. A análise será desenvolvida com recurso a estratégias dos estudos críticos do discurso. Em diálogo com os estudos de Marques (2013) e Dittrich (2014), construímos categorias que permitem observar o desempenho dos jornalistas, as reações da entrevistada e a interação entre os campos. Em consonância com os objetivos do artigo, daremos particular relevo à análise das estratégias discursivas adotadas na construção dos respectivos ethos político e jornalístico perante a opinião pública.

\section{Tensões entre política e jornalismo}

Pierre Bourdieu (2007) define "campo" como um universo social particular constituído por agentes que ocupam posições específicas no interior dessa estrutura. Trata-se de um sistema que pode ser alterado pela ação dos agentes orgânicos ou por forças externas que se impõem. Cada campo possui leis fundamentais, ou seja, valores e pressupostos cognitivos aceitos e reconhecidos pelos próprios agentes. Estes disputam o capital simbólico que lhes garantirá melhores posições hierárquicas por meio de uma disputa travada interna ou externamente. 
No que diz respeito aos campos político e jornalístico, o capital simbólico é constituído, em grande medida, pelo valor da legitimidade. Como assinala Guazina (2011), os jornalistas reivindicam esse valor como forma de justificar e respaldar suas ações no espaço público. No universo político, os agentes travam debates, tanto em momentos eleitorais quanto no quotidiano governativo, no sentido de construir alternativas de governo que sejam legitimadas pela população por meio do voto direto ou — o que nem sempre é verdadeiro —mediante uma representação conectada com o sentimento popular. Nesse sentido, Bourdieu (1998) defende que o campo político é um universo de produção simbólica em que os agentes procuram impor suas categorias de divisão social a partir de visões de mundo específicas.

Por sua vez, o campo jornalístico é um microcosmo social estruturado em torno de valores que configuram a cultura profissional dos agentes do campo. Tais valores são invocados como modo de legitimação do desempenho do jornalismo na esfera pública. Um desses valores assenta nas ideias de que o jornalismo é o representante da opinião pública e de que o seu trabalho reside em fiscalizar o poder político em nome da sociedade (Traquina, 2004). Segundo essa visão, jornalistas seriam fiscalizadores do Poder constituído, com vista ao esclarecimento da sociedade e ao fortalecimento do sentido de participação cidadã nos negócios da Polis. Essas concepções, que estão na base do pensamento político liberal, perspectivam o jornalismo como instituição republicana, atribuindo-lhe um papel de mediador de conflitos e de promotor do esclarecimento público em democracia.

Entretanto, diversos autores têm apontado que o jornalismo nem sempre consegue cumprir efetivamente a missão que o liberalismo político lhe atribuiu. Ao contrário, em muitas ocasiões, contribui para a descredibilização do sistema político e da democracia perante os cidadãos, como mostram estudos nacionais e internacionais sobre a mediatização da corrupção política (Cunha, 2017) ou sobre outras interfaces da comunicação com a política (Prior; Guazina; Araújo, 2016). Quando isso ocorre, o jornalismo se converte em ator institucional cujo desempenho é capaz de criar, e não apenas de mediar, conflitualidades com e entre campos sociais, como o campo político e o campo judicial.

O conflito, ao qual nos referimos, acaba por converter-se em matéria-prima de enriquecimento do próprio capital jornalístico perante a opinião pública. Em sua tese de 
doutoramento, Guazina (2011) argumenta que uma das estratégias mais poderosas de busca de legitimidade pelo jornalismo está na realização de uma "cobertura adversária" em relação à política. Assim, as noções de "contra-poder" ou de "jornalismo cão-de-guarda" deixam de ser unicamente valores constitutivos da cultura profissional dos jornalistas para se transformarem em estratégias de afirmação da legitimidade do campo. Assim, a “cobertura adversária" parece pressupor que a busca da legitimidade dos jornalistas implica um proporcional declínio do capital simbólico do campo político diante da sociedade.

A cobertura da corrupção política surge como o contexto em que esse movimento é verificado com mais nitidez. De fato, o tratamento dado ao tema tem, muitas vezes, o efeito de depreciar a política, fazendo com que haja um aumento da percepção pública de que esse campo é um terreno repleto de pessoas mal-intencionadas e do qual o "cidadão de bem" deve se manter afastado. Ora, no Brasil, essa perspectiva adquire uma vitalidade muito particular, em função dos valores constitutivos da cultura política nacional. Por cultura política, Moisés (1992) entende o conjunto de valores que formatam o imaginário social sobre a política. No caso brasileiro, destacam-se valores como clientelismo, autoritarismo e um enorme grau de desconfiança nos representantes políticos. Esses valores derivam, de acordo com o autor, da própria experiência dos cidadãos com os acontecimentos da esfera política. Se levarmos em conta que o conhecimento público de parte importante desses acontecimentos depende do filtro jornalístico, não será difícil compreender por que o jornalismo possui um papel importante na reafirmação e na naturalização desses valores.

Isso não significa, contudo, que o campo jornalístico deva eximir-se de mostrar os eventuais desvios éticos de certos agentes políticos. Ao contrário, a reafirmação de valores negativos associados à política relaciona-se menos com a exposição da corrupção em si, e mais com o modo como o jornalismo enquadra e apresenta o fenômeno ao público. Em certas ocasiões, a novelização do escândalo (Prior, 2016), que converte casos de corrupção em narrativas melodramáticas, com generalizações, frases de efeito e tons de sensacionalismo fazem com que, em não raras vezes, a política esteja associada, apenas e só, ao universo degradante da corrupção e das diversas formas de desvio. Com efeito, a redução da política ao universo temático da corrupção naturaliza estereótipos que marcam 
a cultura política, com incidência no modo como os cidadãos se relacionam com a própria democracia.

\section{Ethos político e jornalístico na entrevista política televisiva}

A palavra ethos — do grego, que significa "caráter moral" — está diretamente ligada a outro vocábulo, ética, também originada do grego, ethike, que quer dizer "caráter", "costume" e "modo de ser". As primeiras discussões intelectuais sobre a noção de ethos tiveram origem nos estudos de retórica, pelas mãos de Aristóteles, na Grécia, e de Quintiliano e Cícero, em Roma. Para os gregos, o ethos corresponde à imagem criada pelo orador, no momento da enunciação, com o objetivo claro de convencer o auditório. Sófocles, na obra literária Antígona, define ethos como o temperamento dominante da personagem, construído através de vontade, hábitos e paixões. Os romanos, por sua vez, tratam o ethos como um "retrato", dado que a sua significação está ligada diretamente à figura do orador.

Dizer que o ethos é construído no momento da enunciação não significa que a imagem a ele inerente se constitua apenas das palavras proferidas pelo orador. Ao contrário, à dimensão verbal do discurso se juntam outros fatores de ordem paralinguística, que vão das características pessoais de quem fala e de seus interlocutores a elementos de natureza simbólica, ancorados no domínio da cultura. Nesse sentido, Aristóteles ensina que o ethos somente poderá ser entendido por meio da correlação direta desse conceito com outros dois: os conceitos de pathos - que corresponde às paixões sentidas pelos espectadores e, portanto, à capacidade do orador de despertá-las — e logos — que se relaciona com o raciocínio constitutivo do discurso em si, ou seja, com a habilidade de o orador conduzir o auditório no percurso do pensamento em construção.

Partindo desses ensinamentos seminais, propomos pensar a noção de ethos político e jornalístico como construtos identitários ou retratos, na acepção romana, que correspondem ao modo pelo qual o político e o jornalista constroem a sua imagem e são vistos perante a opinião pública. Como destacado na seção anterior, "o político" e "o jornalista" são 
pensados, no âmbito deste trabalho, na sua dimensão coletiva de campo, um microcosmo social dotado de hierarquias, regras e valores que estruturam o modo como este se relaciona com outros microcosmos sociais. Assim, defendemos que parte considerável do processo de construção do ethos desses dois campos está nos contextos interacionais entre ambos, em particular naqueles em que existem modalidades de tensão na interação, como é o caso da entrevista política. A entrevista é um dos gêneros em que o jornalista costuma enfatizar, com maior evidência, certas "mitologias glorificantes" - na expressão de Mário Mesquita (2003) - como a ideia de que a sua atuação profissional está vinculada à missão de representar a opinião pública.

Nesse sentido, Ditrrich (2012) define entrevista jornalística como gênero que busca extrair informações ou posicionamentos de alguém. A entrevista mantém algumas características de conversa, mas se situa num universo mais formal, onde o entrevistado é instado a dizer o que pensa sobre determinado assunto ou como se posiciona a respeito de uma questão relevante. Para além disso, a entrevista é caracterizada por um jogo de poder e de enfrentamento entre os intervenientes. Importa sublinhar que, nesse terreno conflitual, o campo político possui uma aparente desvantagem por causa do alto índice de desconfiança na política. De acordo com uma pesquisa realizada pela Fundação Getulio Vargas, no primeiro semestre de 2016, a confiança dos brasileiros nas instituições midiáticas é muito superior quando comparada às demais instituições da democracia. Por exemplo, enquanto a imprensa escrita ocupa o terceiro lugar, com um índice de confiança de $37 \%$ dos brasileiros, os partidos políticos ocupam a derradeira posição, com $7 \%$ apenas.

A construção do ethos no contexto da entrevista política se dá pela dinâmica de enfrentamento dos campos jornalístico e político frente ao público. No entanto, a falta de confiança na política, como valor que orienta o imaginário social, ajuda a configurar uma espécie de ethos negativo prévio tendente a caracterizar o integrante da classe política. Por essa razão, a entrevista se converte num jogo dialógico com condições de interlocução desiguais entre o campo jornalístico e o político.

Refletindo, especificamente, sobre a entrevista política na televisão, como é o caso do nosso objeto, Maria Aldina Marques (2013) enfatiza que os jornalistas tendem a fazer perguntas que reafirmam o pressuposto ético existente de que eles seriam os representantes 
da opinião pública. Segundo a autora, desde o primeiro momento da transmissão, antes mesmo de a entrevista começar, o jornalista ratifica o público como participante na interação e se coloca como seu porta-voz, ao cumprimentá-lo e ao contextualizar a entrevista. Já ali se constrói uma imagem de autoridade e oponência (Marques, 2013, p. 276).

De toda maneira, uma entrevista deve manter alguns padrões mínimos de respeitabilidade, de forma a que não se transforme numa espécie de interrogatório, cujo objetivo seria não o esclarecimento por meio da argumentação do entrevistado, mas o de encontrar "provas" para referendar suspeitas inicialmente cristalizadas na pergunta do jornalista. A principal diferença entre uma entrevista e aquilo a que chamamos de interrogatório está na ideia de que, no primeiro caso, o jornalista faz a mediação entre a opinião pública e o entrevistado, deixando, todavia, que os posicionamentos do interlocutor se manifestem claramente, ainda que contrariem premissas pressupostas na pergunta. Já no segundo caso, o ato de perguntar se transforma num mero exercício retórico cuja finalidade não é esclarecer, mas referendar um raciocínio prévio construído na pergunta e apresentado ao público como proposta de entendimento de um dado tema a ser, de todas as maneiras, confirmado na resposta. Aqui, portanto, imprime-se uma roupagem de pergunta ao que, na verdade, é uma certeza previamente construída. Em suma, se o ato de perguntar pressupõe a existência de dúvidas, a pergunta-interrogatória procuraria reafirmar concepções já cristalizadas no discurso de quem pergunta.

Assim, diante da relação de tensão estabelecida com o campo jornalístico durante a entrevista, a construção do ethos político depende de uma habilidade de argumentação, que se caracteriza por "uma atividade verbal, social e racional que objetiva convencer um interlocutor sobre a aceitabilidade de um ponto de vista através de um conjunto de proposições que justificam ou refutam a proposição expressa como ponto de partida" (Eemeren; Grootendorst apud Ditrrich, 2014, p. 281). 


\section{Uma análise da entrevista do Jornal Nacional com Dilma Rousseff}

De início, verificaremos as estratégias discursivas utilizadas pelo campo jornalístico na condução da entrevista e na abordagem do principal tema da entrevista: a corrupção política, seguida dos temas saúde e economia e pela apresentação das propostas da candidata, como mostra o quadro 1 .

Tabela 1: Tempo dedicado aos temas

\begin{tabular}{l|l}
\hline Tema & Tempo destinado ao tema \\
\hline Corrupção & 7 minutos e 13 segundos \\
\hline Saúde & 5 minutos e 35 segundos \\
\hline Economia & 3 minutos e 11 segundos \\
\hline Propostas & 1 minuto \\
\hline Tempo total & 17 minutos e 22 segundos \\
\hline
\end{tabular}

Fonte: Elaboração dos autores

Marques (2013) defende que a abertura da entrevista é sempre um dos momentos mais visíveis de afirmação do campo jornalístico perante a opinião pública. Na contextualização realizada, estabelece-se, desde logo, um jogo de oponência entre quem pergunta e quem responde. 
Figura 1: Framing da entrevista com Dilma Rousseff

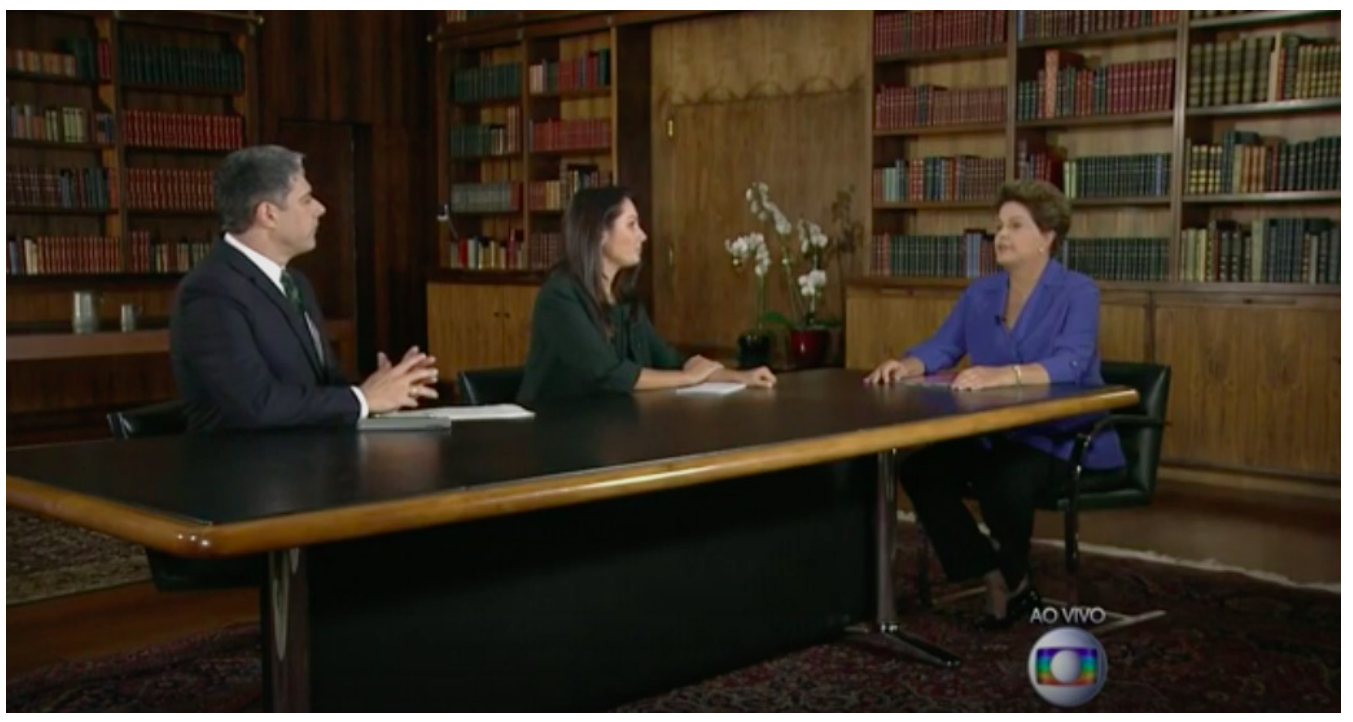

Fonte: GloboPlay

Após saudar a audiência, em um enquadramento em que candidata não aparece, William Bonner enfatiza a ideia de igualdade de tratamento entre os candidatos entrevistados como se observa na lexicalização adotada, demonstrada no quadro 2 , com destaque para as expressões "o que temos feito sempre", "como temos feito com todos os candidatos" - o que evidenciaria respeito aos princípio de imparcialidade e neutralidade. Por outro lado, o jornalista deixa claro, desde logo, a natureza combativa e conflitual que caracterizaria a entrevista, como se verifica nas expressões: "vamos confrontar a candidata", "temas polêmicos".

\section{Quadro 1: Abertura entrevista}

William Bonner: (...) Nós vamos fazer hoje o que temos feito sempre, vamos abordar os temas polêmicos das candidaturas e vamos confrontar a candidata com ações, com o desempenho dela à frente de um cargo público, como temos feito com todos os candidatos. 
Por meio de uma pergunta de 2'10' — visivelmente longa para o tempo exíguo da entrevista, de pouco mais de 17 minutos, a corrupção é o tema que abre a entrevista. Não qualquer corrupção, mas aquela que teria sido praticada no governo da então candidata. Subjaz à pergunta do jornalista a ideia de que a corrupção é um problema a ser resolvido pela via da punição. A pergunta realizada, como se observa no quadro 2, adota uma estratégia discursiva de reificação, que consiste em trazer à baila um conjunto de boas ou más lembranças com vistas a afirmar um certo pressuposto. Essas lembranças foram os casos de corrupção desvelados no governo da candidata, enquadradas, discursivamente, por uma lexicalização negativa, que consiste na repetição das expressões "escândalo" e "esquemas de corrupção" ou "desvios éticos".

\section{Quadro 2: Corrupção como tema principal}

William Bonner: (dirigindo-se à candidata) Candidata, no seu governo, houve uma série de escândalos de corrupção e de desvios éticos. Houve escândalo de corrupção no Ministério da Agricultura, houve escândalo de corrupção no Ministério das Cidades, no Ministério dos Esportes, houve escândalo de corrupção no Ministério da Saúde, no Ministério dos Transportes, houve escândalo de corrupção no Ministério do Turismo, no Ministério do Trabalho... A Petrobras acabou se tornando objeto de duas CPIs no Congresso. A senhora sempre diz que todos esses escândalos foram revelados pela Polícia Federal e estão sendo investigados pela Polícia Federal, que é um órgão do Governo Federal. A questão que eu Ihe faço é a seguinte: Qual é a dificuldade de, desde o início, se cercar de pessoas honestas, que lhe permitam formar uma equipe de governo honesta e que evite esta situação que nós vimos de repetidos casos de corrupção. Não há uma sensação, não pode haver uma sensação no ar, de que o PT descuida da questão ética ou da questão da corrupção?

Fonte: Elaboração dos autores

A natureza da questão permite pressupor que o campo jornalístico estaria a imputar uma responsabilidade, personificada na figura da entrevistada, por todos os esquemas de corrupção que foram descobertos. Por um lado, parece esquecer-se de que a própria Dilma Rousseff afastou um conjunto de ministros que acabaram acusados de práticas ilícitas no primeiro ano de seu governo, o que fez com que alguns jornalistas falassem mesmo numa espécie de "faxina no governo". Por outro, não se fez qualquer distinção entre os processos 
judiciais arquivados por falta de provas e aqueles que seguiram o curso penal ${ }^{1}$. Assim, a responsabilidade por um fenômeno estrutural pareceria restringir-se a uma dimensão de "escolha dos honestos", sem qualquer referência à dimensão institucional, que, no Brasil, tende a eleger, maioritariamente, quem cede às práticas pouco republicanas do sistema político. A título ilustrativo, é interessante levar em consideração o número generalizado de parlamentares que enfrentam pendências com a justiça. De acordo com dados levantados pelo Portal EBC, na plataforma do Projeto "Excelências", da ONG Transparência Brasil, dos 513 deputados presentes na sessão que aprovou a abertura de impeachment contra Dilma Rousseff, em abril de 2016, 298 — ou seja, 59\% da Câmara Federal — já tinham sido condenados ou respondiam a processos na Justiça ou em Tribunais de Contas, muitos deles por corrupção e improbidade administrativa. O parlamentar recordista de processos era o deputado Beto Mansur (PRB-SP), que, na ocasião, integrava a Mesa Diretora da Câmara, com um total de 47 processos, a maioria relacionada com práticas ilícitas da época em que foi Prefeito de Santos, entre 1997 e 2004. Mesmo assim, o deputado tem sido sistematicamente eleito para a Câmara dos Deputados, numa demonstração das fragilidades estruturais do sistema político em vigor².

De igual modo, não há qualquer referência ao papel do eleitor na escolha dos partidos e dos parlamentares, com os quais o governante eleito comporá o governo, devido à natureza amplamente fragmentada do sistema partidário. Encara-se o problema da corrupção, que é estrutural, como questão conjuntural e personificada na figura da Chefe do Executivo. Naturalmente, a dimensão de esclarecimento, que deveria presidir ao trabalho jornalístico, perde-se facilmente em meio a raciocínios simplistas que distanciam o eleitor de uma compreensão holística do fenômeno, com as nuances e contradições que lhe são inerentes.

\footnotetext{
${ }^{1}$ Recorde-se o escândalo que envolveu Antônio Palocci, em maio de 2011, poucos meses depois de Dilma Rousseff assumir o poder e nomeá-lo para chefiar a Casa Civil. Na primeira página do dia 15 de maio de 2011, a Folha de S. Paulo divulgou informação de que Palocci havia multiplicado, em muitas vezes, o seu patrimônio pessoal, sem as devidas explicações. A notícia, repercutida por dias em diversos outros meios de comunicação, acabou instaurando uma crise politica no interior do Palácio do Planalto, que conduziu à queda do ministro, tido como culpado pela imprensa antes mesmo de ser formalmente julgado. Meses depois, a Justiça decretou o arquivamento do processo por falta de provas. A cobertura da FSP, aliás, mereceu análise mais detida em outra oportunidade (Araújo, 2015).

2 Para consultar os dados mais detalhados, vide: http://www.ebc.com.br/noticias/politica/2016/04/cerca-60-dosdeputados-federais-que-julgaram-dilma-tem-pendencias-na. Acesso em: 24/05/2017. Para uma discussão sobre a influência da mídia na queda de ministros no primeiro ano do governo Dilma, vide: Gramacho 2015).
} 
Outra questão importante a ser destacada - e que corrobora a visão simplista e até estereotipada de apresentação do tema que abre a entrevista — é a ideia de que os esquemas de corrupção seriam algo, necessariamente, ruim para o país. De fato, a corrupção é algo que degrada os signos da República e coloca a democracia em estado de deterioração. No entanto, os entrevistadores parecem confundir a existência da corrupção - algo histórico e estrutural no país - com a consciência pública sobre ela - algo que depende da sua exposição. Segundo Thompson (2002), somente quando exposta, é que a corrupção se transforma em escândalo. Isso ocorre porque a exposição, realizada após uma investigação judicial ou jornalística, reúne o elemento da exposição pública do fenômeno com a consequente reprovação moral. São esses dois elementos que, para o autor, configuram o início de um escândalo. Assim, a corrupção, enquanto prática ilícita, se não descoberta e exposta, jamais se converterá em escândalo. A história brasileira mostra que foi isso o que aconteceu durante anos no país, em particular durante a ditadura, quando não havia liberdade de imprensa, tampouco condições institucionais para uma investigação dessas práticas.

Porém, no caso em tela, o campo jornalístico trata corrupção e escândalo como sinônimos, perdendo de vista a ideia de que os diversos escândalos aos quais fazem referência, na pergunta, só existem por causa dos mecanismos de fiscalização desenvolvidos na última década e para os quais o governo da entrevistada contribuiu de forma significativa. Desse modo, do ponto de vista teórico, ao enquadrar a entrevistada num ambiente de responsabilização pela corrupção, sem ressaltar os instrumentos criados pelo seu governo para combatê-la, os entrevistadores caem num franco paradoxo. Confunde-se, então, mais investigação com maior grau de corrupção. Essa questão é, aliás, salientada por Michael Johnston, atualmente um dos principais especialistas internacionais no estudo da corrupção. Em entrevista à revista Época, em abril de 2015, o autor destaca que, no Brasil, as notícias sobre corrupção são encaradas como algo ruim, quando deveriam ser vistas como algo que só existe graças às condições institucionais para realizar investigações.

Apresentar o problema de modo personificado e, muitas vezes, seletivo - este ou aquele político, este ou aquele partido —, também revela uma abordagem falsamente moralista. Quando o campo jornalístico apresenta o problema de modo simplista, desprovido da 
dimensão positiva que os mecanismos de combate revelam, acaba por investir na construção de uma abordagem calcada numa espécie de pathos da indignação, o qual contribui, tão somente, para depreciar o ethos político, já fragilizado pela associação unilateral da corrupção a um problema da política, e não uma questão pulverizada pelo tecido social.

\section{Quando a imagem é abalada: o ethos político na entrevista com Dilma Rousseff}

Neste segundo momento de análise, observaremos, em especial, a postura do campo político personificado na figura de Dilma Rousseff. O objetivo é mapear as estratégias discursivas utilizadas pela candidata para lidar com as questões realizadas pelo campo jornalístico, além de identificar os momentos de tensão mais evidentes na interação entre os campos. Em diálogo com o estudo de Marques (2013), propomos uma classificação das respostas da candidata em duas categorias de análise que permitem perceber se ela aceita em parte ou refuta completamente as premissas implícitas nas questões. No que tange aos jornalistas, o objetivo é entender se eles aceitam a contra-argumentação da entrevistada ou se reiteram as premissas subjacentes às questões. A tabela 2 analisa as principais premissas encontradas nas perguntas, focando no desempenho dos participantes da entrevista em relação a elas.

Tabela 2: Planilha de análise da entrevista com Dilma Rousseff

\begin{tabular}{l|l|l|l}
\hline Tema & $\begin{array}{l}\text { Premissas } \\
\text { na pergunta }\end{array}$ & $\begin{array}{l}\text { Entrevistada sobre as } \\
\text { premissas }\end{array}$ & $\begin{array}{l}\text { Entrevistadores } \\
\text { sobre as } \\
\text { premissas }^{3}\end{array}$ \\
\hline Corrupção & $\begin{array}{l}\text { A corrupção é um grave } \\
\text { problema do governo }\end{array}$ & Refuta completamente & Reitera a premissa \\
\hline
\end{tabular}

3 Para efeitos de classificação, foram consideradas apenas as perguntas que introduziram os temas. Aqui, não consideramos as perguntas feitas sobre o mesmo tema, como as reformulações ou a reafirmação da primeira pergunta. 


\begin{tabular}{|c|c|c|c|}
\hline & $\begin{array}{l}\text { "No seu governo, houve uma } \\
\text { série de escândalos de } \\
\text { corrupção e de desvios éticos" } \\
\text { A candidata é a responsável e o } \\
\text { partido conivente } \\
\text { "Qual é a dificuldade de, desde } \\
\text { o início, se cercar de pessoas } \\
\text { honestas?" }\end{array}$ & $\begin{array}{l}\text { "Fomos o governo que } \\
\text { mais estruturou os } \\
\text { mecanismos de } \\
\text { fiscalização" }\end{array}$ & $\begin{array}{l}\text { “Corrupção não é o } \\
\text { único problema” }\end{array}$ \\
\hline Saúde & $\begin{array}{l}\text { Os investimentos não } \\
\text { resolveram os problemas da } \\
\text { saúde } \\
\text { "O seu governo diz que sempre } \\
\text { investiu muito na área de saúde, } \\
\text { e essa continua sendo } \\
\text { exatamente a maior } \\
\text { preocupação dos brasileiros (...)” } \\
\text { O tempo de governo foi mais do } \\
\text { que suficiente para resolver os } \\
\text { problemas } \\
\text { "(...) isso depois de } 12 \text { anos de } \\
\text { governos do PT, ou seja, mais } \\
\text { de uma década. }\end{array}$ & $\begin{array}{l}\text { Aceita parcialmente } \\
\text { "Nós ainda temos } \\
\text { muitos problemas e } \\
\text { desafios a enfrentar na } \\
\text { saúde" }\end{array}$ & $\begin{array}{l}\text { Reitera a premissa } \\
\text { "A minha colocação } \\
\text { era... } 12 \text { anos, } 12 \\
\text { anos de governo, } 3 \\
\text { mandatos..." }\end{array}$ \\
\hline Economia & $\begin{array}{l}\text { O diagnóstico da candidata } \\
\text { sobre as causas da crise está } \\
\text { errado } \\
\text { "a senhora considera justo ora } \\
\text { culpar o pessimismo, ora culpar } \\
\text { a crise internacional pelos } \\
\text { problemas?" } \\
\text { O governo tem responsabilidade } \\
\text { pela crise } \\
\text { "o seu governo não tem } \\
\text { nenhuma responsabilidade nos } \\
\text { resultados que estão aí?" }\end{array}$ & $\begin{array}{l}\text { Refuta } \\
\text { complementamente } \\
\text { "Não sei de onde são os } \\
\text { seus números" } \\
\text { "Todos os índices } \\
\text { indicam uma } \\
\text { recuperação no } \\
\text { segundo semestre" }\end{array}$ & $\begin{array}{l}\text { Reitera a premissa } \\
\text { "Isso não é ser } \\
\text { otimista em } \\
\text { contrapartida ao } \\
\text { pessimismo que a } \\
\text { senhora critica?" } \\
\text { "Mas o resultado no } \\
\text { momento é muito } \\
\text { ruim, candidata" }\end{array}$ \\
\hline Propostas & Sem premissas & - & - \\
\hline
\end{tabular}

Fonte: Elaboração dos autores

Em primeiro lugar, como ocorre em toda entrevista política, o desempenho da candidataentrevistada procura construir ou gerenciar, da melhor maneira, uma imagem que seja favorável diante do público, terceiro interveniente daquela estrutura comunicacional. A 
cada pergunta, a candidata procurou desconstruir os argumentos do campo jornalístico, propondo uma contrainterpretação aos temas em discussão. Trata-se de uma estratégia de refutação pelo discurso no sentido de subverter o ethos negativo que a pergunta estruturada também em torno de pressupostos paralinguísticos, por exemplo, os valores da cultura política - estabelece previamente. No caso de Dilma Rousseff, a análise mostra que ela refuta completamente a maioria das premissas subjacentes aos questionamentos, a começar pela pergunta sobre os escândalos de corrupção, que se converte em tema principal da entrevista, quer pelo tempo que lhe foi destinado, quer pela posição tópica, isto é, de primeira questão.

Ao responder a essa primeira indagação, Dilma Rousseff é enfática ao refutar as premissas de que ela seria a responsável pela corrupção ou de que o seu partido, o PT, seria conivente com o problema. No início de sua argumentação, conforme o quadro 3, as expressões "não pode não" e "sabe por quê?", deixam claro, respectivamente, a negação da premissa e a introdução de um raciocínio que procura desconstruí-la por meio de uma explicação introduzida pela conjunção "por quê".

\section{Quadro 3: Interação na entrevista/corrupção}

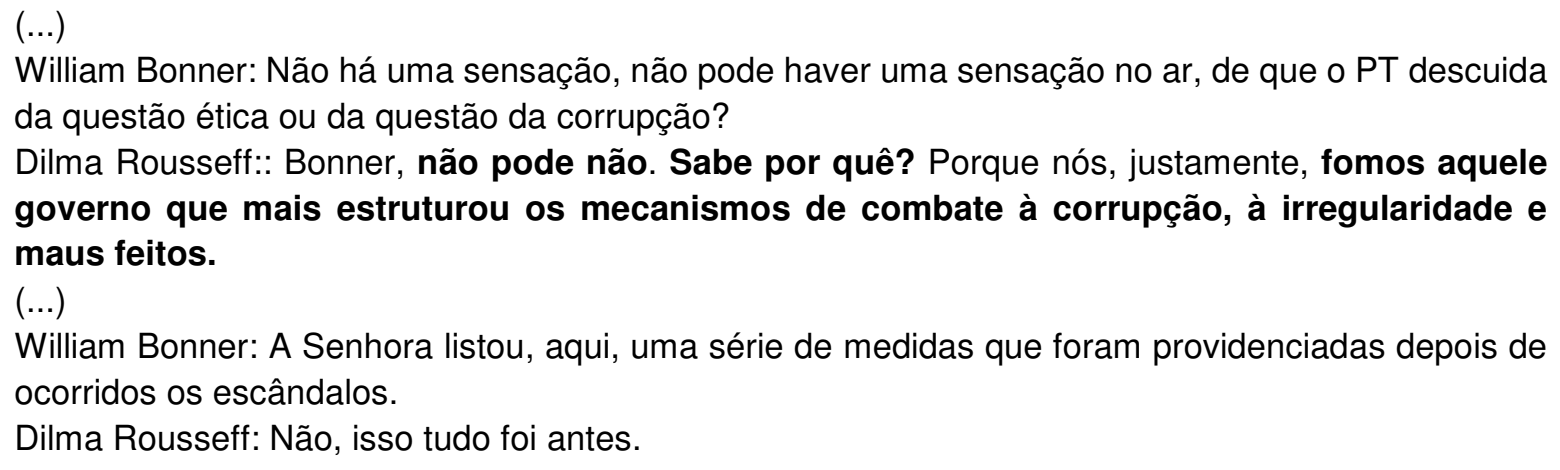

Fonte: Elaboração dos autores

Seguindo o pensamento de Dittrich (2014, p.279), a entrevistada elenca um conjunto de pontos positivos que contrariam a percepção negativa exposta na pergunta, defendendo que o seu governo "foi o que mais estruturou os mecanismos de combate à corrupção, a irregularidades e malfeitos" (2'44') . A entrevistada questiona a premissa, apresentando 
argumentos diferentes como meio para uma leitura alternativa ao tema proposto, na tentativa, portanto, de desfazer o ethos de corrupta ou conivente.

O mesmo ocorre na abordagem ao tema "saúde", o segundo eixo temático da entrevista. Diante da premissa de que a saúde pública no Brasil possui problemas que não foram resolvidos, apesar de três mandatos consecutivos do Partido dos Trabalhadores, Dilma Rousseff aceita parcialmente a ideia, mas procura suavizar parte da premissa, implícita na questão, de que teria sido tempo suficiente para que o governo resolvesse os problemas. Assim como na resposta à primeira pergunta, enumera pontos positivos relacionados ao tema. Nesse momento, a entrevistada tenta se aproximar do público que quer cativar com sua resposta, insinuando que está atenta às pesquisas e à principal reclamação das pessoas, que, em sua opinião, é a falta de médicos. Nessa linha de raciocínio, como se observa no quadro 6, cita o programa Mais Médicos e o número exato de médicos que foram contratados, numa estratégia que evidencia conhecimento da questão.

\section{Quadro 4: Interação na entrevista/saúde}

Patrícia Poeta: Não foi tempo suficiente pra colocar esses problemas nos trilhos, não?

Dilma Rousseff: Olha, Patrícia, nós tivemos e ainda temos muitos problemas a enfrentar e desafio a enfrentar na saúde. (...) Na sequência, chamamos médicos cubanos através da OPAS e aí conseguimos chegar a 14.462 médicos, que, pelos dados da OMS, correspondem a uma capacidade de atendimento de 50 milhões de brasileiros.

(...)

Patrícia Poeta: A senhora diria que, então, diante dos nossos telespectadores, que hoje enfrentam filas e filas nos hospitais, muitas vezes são atendidos em macas, que muitas vezes não conseguem fazer um exame de diagnóstico, que a situação da saúde do nosso país, hoje, é minimamente razoável? Depois de doze anos.

Dilma Rousseff: Não acho. Não acho. Até porque, Patrícia, o Brasil precisa também de uma reforma federativa. Porque há responsabilidades federais, estaduais e municipais. Nós assumimos, no caso do Mais Médicos, o atendimento aos postos de saúde como uma, uma responsabilidade basicamente. Nós assumimos como federal. Ela é uma responsabilidade compartilhada. Mas assumimos, como federal, porque temos mais recursos.

Fonte: Elaboração dos autores

Apesar da tentativa da candidata de reverter o abalo da imagem, devido à negatividade da abordagem da questão, Patrícia Poeta e William Bonner parecem interessados apenas em extrair da entrevistada a concordância de que a situação da saúde "não é minimamente 
razoável". Esse é um caso emblemático de uma pergunta que visa, tão somente, obter a confirmação de uma premissa expressa anteriormente. Assim, não permite que o entrevistado apresente suas propostas para a área, tampouco que diga com que recursos o fará ou de que maneira. A estratégia consiste em perguntar para comprovar, uma técnica retórica que transforma o questionamento numa afirmação velada. Nesse caso concreto, a dimensão imagética ajuda a perceber o que estamos enfatizando. Ao reformular a questão, com o mesmo sentido, mas reafirmando a premissa de que os governos consecutivos do PT teriam tido tempo suficiente para resolver os problemas da saúde - e esquecendo-se da divisão de responsabilidades que a Constituição impõe entre Governo Federal, Estados e Municípios, apesar de a candidata insistir no ponto, Patrícia Poeta chega a pôr o dedo em riste na direção da entrevistada, como vemos na imagem abaixo, construindo um universo de tensão entre os campos na luta pela atenção e confiança do público.

\section{Figura 2: Framing da entrevista/Tensão na interação}

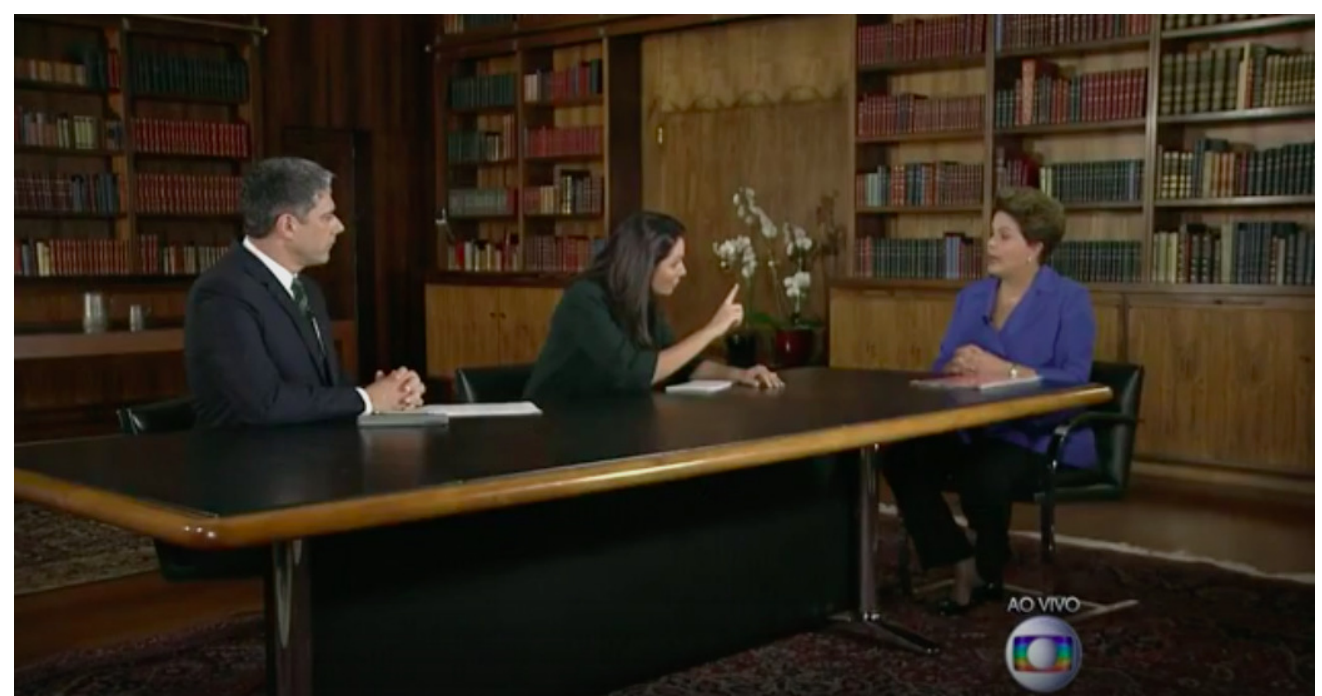

Fonte: GloboPlay

\section{Conclusões}

A análise que acabamos de desenvolver é bastante reveladora daquilo que Pierre Bourdieu (2007) define como sendo um papel ativo do jornalismo na constituição do ethos político. Em se tratando de uma entrevista realizada em pleno período eleitoral, esse papel se torna 
ainda mais fundamental na medida em que parte importante dos eleitores encontra, na cobertura realizada, um ponto de referência para a definição de posições políticas e para a construção ou reafirmação de certas visões sobre a política e o sistema político. Diante disso, a análise da entrevista com Dilma Rousseff possui características que, em conjunto, juntam-se a outros esforços da área de comunicação e política no sentido de compreender como o jornalismo constrói discursivamente a política e, desse modo, interfere, na própria qualidade do relacionamento dos cidadãos com o universo democrático.

Uma das questões mais prementes, na entrevista analisada, é a aposta em abordagens pouco desenvolvidas, que não contemplam as complexidades do sistema político brasileiro, como a ampla pulverização partidária ou as dificuldades impostas por um pacto federativo ineficiente, que coloca a tônica das questões no governo central, esquecendo-se de responsabilidades constitucionalmente atribuídas a outras esferas da Federação. É o caso do tratamento dado ao tema da saúde, cuja responsabilidade para os problemas é totalmente atribuída, durante a entrevista, ao Governo Federal, apesar da tentativa da entrevistada de explicitar a partilha de responsabilidades. O mesmo ocorre com o tema da corrupção política, cuja topicalização, ou seja, a figuração como tema mais importante da entrevista, situa o fenômeno como o problema mais grave do governo Dilma Rousseff e, por conseguinte, como o desafio mais importante do país naquele momento.

Em ambos os casos, as perguntas realizadas visaram confirmar pontos de vista ou, como chamamos anteriormente, premissas subjacentes ao discurso do campo jornalístico. Em vez de fornecer espaço para explicações ou para um discurso propositivo, as constantes interferências no raciocínio da entrevistada, bem como a estratégia de repetição das ideias implícitas na questão, deixam perceber que o objetivo do campo jornalístico, no caso em análise, não era esclarecer os eleitores, mas confirmar hipóteses anteriormente aventadas. De entrevista, o diálogo transforma-se em interrogatório. Com isso, o jornalismo se afasta da função primordial de esclarecimento da opinião pública, como valor constitutivo do seu papel em democracia, segundo o ideal do liberalismo, que funda o Estado de Direito moderno. Em nossa opinião, aposta-se no enfrentamento incisivo, por vezes, agressivo, que não deixa espaço para uma discussão minimamente aprofundada de temas importantes para o país. 
Em último caso - e este parece ser um principais efeitos da entrevista analisada, o campo jornalístico contribui para a reafirmação do atual movimento de negação da política, visto que parte significativa dos questionamentos está incrustada de valores depreciativos que configuram a cultura política nacional e que acabam por associar o campo político a uma esfera ineficiente para a resolução dos problemas do país e a um terreno de práticas vis e reprováveis. Em suma, a desconfiança na política, como valor que estrutura a relação interacional da entrevista, está presente, porque o campo jornalístico também compartilha desse e de outros valores, de forma que o processo de discursivização da política ali delineado naturaliza e prolonga esses valores no tempo.

\section{Referências}

ARISTÓTELES. Ética a Nicômaco. 4. ed. São Paulo: Nova Cultural, 1991;

BOURDIEU, Pierre. O Poder Simbólico. Rio de Janeiro: Bertrand Brasil, 2007;

CUNHA, Isabel Ferin. Democracia e corrupção mediatizadas. In: MOREIRA, Ana; ARAÚJO, Emília; SOUSA, Helena (orgs.). Comunicação e Política: tempos, contextos e desafios. Braga: CS Edições, pp. 61-90, 2017.

DITTRICH, José Ivo. O Ethos na Entrevista Jornalística: Refazer e Desfazer uma Imagem. Cadernos de Letras da Uff - Dossiê: Palavra e Imagem. Rio de Janeiro, v. 1, n. 44, p.277-293, 2012. Disponível em:

<http://www.cadernosdeletras.uff.br/joomla/images/stories/edicoes/44/artigo15.pdf>. Acesso em: 16 abr. 2017;

ÉPOCA. Michel Johnston: "É melhor fazer pouco, mas fazer direito". 14 abr. 2015. Disponível em: http://epoca.globo.com/ideias/noticia/2015/04/michael-johnston-e-melhor-fazer-pouco-masfazer-direito.html. Acesso em: 20/05/2017.

FGV DIREITO SP. Relatório ICJBrasil. 2016. Disponível em: $<$ http://bibliotecadigital.fgv.br/dspace/bitstream/handle/10438/17204/RelatorioICJBrasil_1_sem_2016.pdf?sequence=1\&isAllowed=y>. Acesso em: 16 abr. 2017

GRAMACHO, Wladimir. Ciclos de crise de imagem de ministros de 2011 e o poder da imprensa. Anais do VI Congresso da Associação de Pesquisadores em Comunicação e Política. Rio de janeiro, 22 e 24 de abril de 2015. Disponível em: http://www.compolitica.org/home/wpcontent/uploads/2015/04/GT8-GRAMACHO.pdf

GUAZINA, Liziane. Jornalismo em busca de credibilidade: a cobertura adversária do Jornal Nacional no Escândalo do Mensalão. 256f. Tese (Doutorado). Faculdade de Comunicação, Universidade de Brasília, 2011; 
LIMA, Venício Arthur. As entrevistas do Jornal Nacional. In: Carta Maior. Disponível em: http://www.cartamaior.com.br/?/Coluna/As-entrevistas-do-Jornal-Nacional/31680. Acesso em: 25/02/2017.

MARQUES, Maria. Aldina. Imagens (entre)vistas. A construção de identidades nas entrevistas políticas televisivas. In: SILVA, Augusto Soares; MARTINS, José Cândido; MAGALHÃES, Luisa; GONÇALVES, Miguel. Comunicação Política e Económica. Dimensões Cognitivas e discursivas. Braga: Publicações da Faculdade de Filosofia da Universidade Católica Portuguesa, pp. 271-287

MESQUITA, Mário. O quarto equívoco. Coimbra: Almedina, 2003.

MOISÉS, José Álvaro. "Democratização e Cultura Politica de massas no Brasil". In: Lua Nova. n. 26 p. 5-51, 1992.

PRIOR, Hélder; GUAZINA, Liziane; ARAÚJO, Bruno. Diálogos Lusófonos em comunicação e política. Covilhã, Portugal: Labcom.ifp, 2016. Disponível em: <http://www.labcomifp.ubi.pt/ficheiros/201611021430-201611_dialogoslusofonos_hp.pdf>. Acesso em: 16 abr. 2017

PRIOR, Hélder. Esfera pública e escândalo político. A face oculta do poder. Lisboa: Media XXI, 2016.

SÓFOCLES. Antígone. [S.I.]: eBooksBrasil, 2005. Disponível em: <http://www.ebooksbrasil.org/adobeebook/antigone.pdf>. Acesso em: 16 abr. 2017

TAVARES, Flavia. Michael Johnston: "É melhor fazer pouco, mas fazer direito". 2015.

Disponível em: <http://epoca.globo.com/ideias/noticia/2015/04/michael-johnston-e-melhor-fazerpouco-mas-fazer-direito.html>. Acesso em: 16 abr. 2017;

THOMPSON, John. O escândalo político: poder e visibilidade na era da mídia. Petrópolis: Editora Vozes, 2002.

TRAQUINA, Nelson. Teorias do Jornalismo. Florianópolis: Insular, 2004

\section{Os autores}

Bruno Araújo é doutorando em Comunicação da Universidade de Brasília (UnB) e pesquisador do Núcleo de Estudos sobre Mídia e Política da UnB. brrunoaraujo@gmail.com

Adriano Lima Feitosa é graduando em Jornalismo na Universidade de Brasília (UnB). adriano.llf@gmail.com

Bruno Henrique Oliveira é graduando em Letras na Universidade de Brasília (UnB). bhnobrega@gmail.com

Giovanna Maria Silva é graduanda em Jornalismo na Universidade de Brasília (UnB). giovannamariajs@gmail.com

Úrsula Barbosa Rodrigues é graduanda em Jornalismo na Universidade de Brasília (UnB). ursulabarbosa1@gmail.com 